\title{
Reproductive Goals and Family Planning Attitudes in Pakistan: A Couple-level Analysis
}

\begin{abstract}
NAUSHIN MAHMOOD
Based on the responses of 1260 matched couples in the 1990-91 Pakistan Demographic and Health Survey, this study examines how congruent wives' and husbands' attitudes towards fertility and family planning are, and to what extent the similarity or difference in attitudes affects their reproductive control behaviour. The results show that about 60 percent of the couples have given similar responses (agreeing either positively or negatively) to several fertility-related questions, whereas the remaining 40 percent differ in their attitudes. Multivariate analyses indicate that a couple's joint approval of family planning, husband's desire for no more children, and spousal discussion about family planning stand out as the strongest predictors of contraceptive use. These findings clearly suggest that the role of couple agreement is important in promoting the use of family planning, and that men should be made as equal targets of such programmes in Pakistan.
\end{abstract}

\section{INTRODUCTION}

Studying the nature and extent of women's and men's differences in fertility attitudes is important for understanding the process of reproductive change and family planning issues. Research literature suggests that family size desires and fertility outcome have an important dimension of gender relations, especially in cultures were men's role in family decision-making is dominant [Ezech (1993); Thomson et al. (1990); Sathar et al. (1988); Mason and Taj (1987); Mott and Mott (1985); Beckman (1983); Coombs and Fernadez (1978)]. Nevertheless, most of the studies done on fertility desires and patterns of reproductive control are based on interviews with married women only, with the implicit assumption that characteristics and attitudes of women are reflective of their husbands and can serve as a proxy for those of a couple. In actuality, this may not hold true. Some studies, utilising information on both wives Islamabad.

Naushin Mahmood is Chief of Research at the Pakistan Institute of Development Economics,

Author's Note: This article is the revised version of a paper presented at the International Union for the Scientific Study of Population seminar on "Comparative Perspectives on Fertility Transition in South Asia”, December 17-20, 1996, Islamabad, Pakistan. I have benefitted from comments by Karin Ringheim, Ghulam Yasin Soomro, and other participants of the seminar. Comments by an anonymous referee of this journal are highly appreciated. The responsibility for any error or omission in the paper lies with the author. 
and husbands, have found significant divergences in their responses about fertility preferences and family planning attitudes [Salway (1994); Koening, Simons and Misra (1984); Coombs and Chang (1981)], while some others point towards small differences, on average, in reproductive goals of women and men [Mason and Taj (1987)]. The evidence as a whole suggests that aggregate information on women alone is not fully representative of the attitudes and opinions of married couples as it largely ignores an important component of the context in which fertility decisions are made, attitudes are formed, and reproductive control behaviour takes place.

\section{THEORETICAL CONSIDERATIONS}

Theoretically, the arguments for the importance of distinguishing women's reproductive goals from those of husbands or households are based on the state of fertility transition and demographic motivations emerging within the population community. In relatively modern and gender-egalitarian societies, one would expect greater agreement in fertility and family planning attitudes between spouses. This could be because with more widespread schooling, increased opportunities for wage work, and equality of gender relations in these societies, women and men are likely to have similar reproductive interests: women are likely to desire small families due to their own sources of support and status besides children, and are less likely to bear the unique cost of childbearing and health risks, while men may want fewer children due to the disproportionate economic and social advantages accruing to them. Additionally, modern social and economic conditions are likely to promote husband-wife interaction and communication resulting in greater congruence in their fertility attitudes and behaviour.

However, it is also argued that women and men could have similar fertility preferences even in traditional and highly patriarchal settings. Men may desire large families because they seek economic benefits and social prestige and power in having children, while women could have equally high fertility desires due to advantages of old-age support, enhanced status within the family, etc.

It is also possible that similarity in reproductive goals among women and men may occur due to the impact of socialisation and prevailing social norm. In societies where community norms favour high fertility or oppose reproductive control, most couples are likely to desire large families. The reverse would be true in societies at the late stage of fertility transition where small family norm prevails among the majority of population.

Added to these arguments is the related question of how a couple's agreement or differences in fertility and family planning attitudes are translated into effective reproductive control behaviour. A few studies focusing on this issue have found that the reconciliation of differences and the subsequent impact on fertility outcome is a 
complex negotiation process [Lloyd (1993); Govindasamy and Malhotra (1994)]. This process could either be subtle and compromising in adopting attitudes closer to those of their partners, or could involve direct dominance and control of the stronger and powerful partner over the other, as happens in many patriarchal societies where mostly women reconcile with the wishes and fertility desires of their husbands. Hence, it is of interest to understand how the constraints of gender inequality in less modern societies like that of Pakistan influence a couple's reproductive attitudes and family planning behaviour.

\section{THE SOCIAL CONTEXT IN PAKISTAN}

Examining differences in fertility-related attitudes of both women and men is pertinent to demographic concerns in Pakistan where family systems are patriarchal and patrilineal with strong gender biases, fertility levels are high with greater demand for sons than daughters (TFR around 5.4 during 1990-95), and contraceptive use is low (nearly 18 percent during 1994-95). There is evidence, however, of a further rise in contraceptive use-upto 24 percent in more recent years, implying a greater potential for future fertility decline [National Institute of Population Studies (1997)].

Overall, the country has inadequate provision of social services and basic infrastructure, particularly in rural areas where the majority of population lives. As such, levels of education and literacy are extremely low, especially for women, and gender inequality is perpetuated in the system through various forms of discrimination and disadvantages against girls. The relatively less favourable position of women in the economic and decision-making spheres inhibits them to make choices about family size and family planning. Additionally, Pakistani society and culture, in common with most of South Asia, exhibits strong son preference, which contributes towards the achievement of large family size among many couples [Arnold (1992); Nag (1991)].

The gender-related aspects of reproductive attitudes and issues have not been widely examined in Pakistan hitherto, a gap which this study addresses. Given the context of a less developed and early-transition Pakistani society, where gender inequality and fertility are typically high, there are many reasons to expect women and men (or couples) to differ in their reproductive goals and attitudes. In situations where women want fewer children than men, or want to stop childbearing but fail to use contraception because their husbands want additional children and/or have more power than wives to exert independent effects on reproductive choices, studying the differences in women's and men's (or couples) fertility goals and family planning attitudes provides the bases for understanding the reasons for the existence of KAP-gap in family planning. This is an issue of great relevance for the enhancement of the family planning programme in Pakistan. It may also be expected that with social and economic changes occurring in the society, women's ability to control fertility increases, which is 
likely to reduce the KAP-gap and accelerate the pace of fertility decline.

Empirical evidence on couple-level analysis of reproductive attitudes and related issues is extremely limited in Pakistan. Among the few studies that have used wives' and husbands' information, Shah (1974) examines the role of interspousal communication in couples' adoption of contraceptive use and finds a strong relationship between the two variables. ${ }^{1}$ Mahmood and Ringheim (1993) have studied the impact of selected socioeconomic and family planning variables on desired additional fertility and contraceptive use and find some differences in the significance of predictors when the results of wives' and husbands' individual samples are compared. ${ }^{2}$

Given these demographic and cultural patterns, and assuming that gender roles and power relations are important in influencing reproductive control patterns in Pakistan, we examine, at the couple level, the extent of agreement about fertility desires, preference for sons, and family planning attitudes, and see how it reflects or contributes towards the adoption of fertility control behaviour of couples at the household level.

This paper, therefore addresses two specific questions:

(1) How and in what way do married women and men differ in their desired fertility, family size ideals, and contraceptive attitudes?

(2) What factors explain the similarity or differences in husband-wife attitudes to family size and contraceptive use, and how relevant are individual characteristics as opposed to other couple variables in explaining their reproductive control behaviour?

\section{DATA AND METHODS}

The data for this study are from the Pakistan Demographic and Health Survey of 1990-91, a nationally representative survey of 6,611 ever-married women aged 15-49 years, and a one-third sub-sample of husbands. ${ }^{3}$

The present study has used information on 1260 matched couples who gave independent responses to similar questions on attitudes and preferences about family size and family limitation, and for whom data are available on all variables of interest. ${ }^{4}$

${ }^{1}$ The study was based on couple-level information from the National Impact Survey Data of 1968-69, which found that if both spouses were reached and provided family planning education, the communication between couples increased, which in turn was significant in increasing the adoption of family planning.

${ }^{2}$ The analysis has been done for separate samples of wives and husbands and, therefore, does not reflect the reproductive attitudes and behaviour of couples at the household level.

${ }^{3}$ For details on the design and sample of husbands' survey, see Pakistan Demographic and Health Survey, 1990-91.

${ }^{4}$ The data set was evaluated for its suitability for the analysis of couple behaviour and it was found that the characteristics of the reduced sample of matched wives did not differ significantly from those in the total sample. 
In the analysis that follows, couples' differences in fertility attitudes and preferences are measured by the simple percentage response on these variables. The interest here is to examine the extent of agreement (or disagreement) on each variable and see how it ultimately explains the reproductive control behaviour of couples. For this purpose, bivariate relationships between reproductive goals, family size ideals of both wives and husbands, and contraceptive use are examined.

These results are then re-examined using logistic regressions to get more precise answers for the questions addressed in the study. In such an analysis, the dependent variable is current contraceptive use, defined by whether both spouses or either spouse is using some form of contraception, and zero otherwise. The variables used in this analysis are described and discussed in Tables 2 and 3.

\section{RESULTS}

\section{Individual Characteristics of Wives and Husbands}

Table 1 shows the distribution of the individual characteristics of wives and husbands in the selected sample and the percentages of the matched responses of couples for each category of variable used for this analysis. As the table shows, most of the women are between the age groups of 15-29 and 30-39 years (77.8 percent), whereas a majority of husbands fall between 30-39 and 40-years-and-older age groups (75.4 percent). In general, husbands are about 7 years older than their wives in the sample under study.

In terms of education, husbands appear to be more educated than wives, as 49 percent of husbands have attained some level of education as compared to only 17.5 percent of wives. Lack of exposure to formal schooling among women reinforces the argument of their low status in education and other spheres of life. With respect to fertility desires and preferences, wives are more likely to want no more children, as nearly 42 percent of wives compared to 33 percent of husbands want no additional child. On the other hand, a higher proportion of husbands either want more children or have given the 'upto God' responses to the fertility desire or ideal family size questions. Could this be interpreted as an evidence for lower motivation among husbands than wives for fertility control behaviour? This is the question that will be examined in terms of its implications for the adoption of family planning.

Data pertaining to family planning attitudes and practices indicate that more husbands than wives have given favourable responses to family planning questions. For example, about 66 percent husbands approve of family planning as compared to 54 percent wives. With respect to ideal family size, about 11 percent of both wives and husbands want three or fewer children, and 28 percent of wives and 24 percent of husbands want four or more children. It is interesting to note that 60.8 percent of wives 
Table 1

Percentage Distribution of Wives' and Husband's Individual Characteristics and Percentage of Couples in Agreement

\begin{tabular}{|c|c|c|c|}
\hline Characteristics & $\begin{array}{c}\text { Wives } \\
(\mathrm{N}=1260)\end{array}$ & $\begin{array}{l}\text { Husbands } \\
(\mathrm{N}=1260)\end{array}$ & $\begin{array}{c}\text { Matched Response } \\
\text { (Percent in } \\
\text { Agreement) }\end{array}$ \\
\hline \multicolumn{4}{|l|}{ Current Age } \\
\hline $15-29$ & $46.5(585)$ & $24.6(310)$ & 23.4 (295) \\
\hline $30-39$ & $31.3(394)$ & 34.4 (433) & $13.8(173)$ \\
\hline $40+$ & $22.2(281)$ & $41.0(517)$ & $21.3(269)$ \\
\hline (Mean) & (31.5 years) & (38.5 years) & \\
\hline \multicolumn{4}{|l|}{ Education } \\
\hline None & $82.5(1040)$ & $51.1(643)$ & $49.0(617)$ \\
\hline Primary and Middle & $10.5(132)$ & $28.6(360)$ & $4.1(51)$ \\
\hline Secondary and Higher & 7.0 (88) & $20.4(256)$ & $5.9(74)$ \\
\hline \multicolumn{4}{|l|}{ Fertility Desires } \\
\hline Want More Children & $44.3(558)$ & $47.1(594)$ & $33.3(420)$ \\
\hline No More Children & $42.3(532)$ & 33.5 (421) & $25.6(322)$ \\
\hline Upto God/DK & $13.5(170)$ & $19.5(245)$ & $4.7(59)$ \\
\hline \multicolumn{4}{|l|}{ Ideal Family Size (IFS) } \\
\hline 0 - 3 Children & $10.9(138)$ & $11.0(139)$ & $4.5(57)$ \\
\hline 4 and More & $28.2(356)$ & $24.0(302)$ & $10.5(133)$ \\
\hline Upto God & $60.8(766)$ & $65.0(819)$ & $45.5(574)$ \\
\hline (Mean IFS) & (4.2) & & (4.6) \\
\hline \multicolumn{4}{|l|}{ Sex Preference for Next Child } \\
\hline Boy & $48.1(268)$ & $47.5(278)$ & $31.9(132)$ \\
\hline Girl & $6.3(36)$ & 3.9 (23) & 3.1 (5) \\
\hline Either & $45.6(254)$ & $48.6(285)$ & $31.8(131)$ \\
\hline \multicolumn{4}{|l|}{ Family Planning Attitudes } \\
\hline Approve & $54.6(688)$ & $66.4(837)$ & 41.2 (519) \\
\hline Disapprove & $45.4(572)$ & 33.6 (423) & $20.2(254)$ \\
\hline Knowledge of FP (Yes) & $76.3(961)$ & $78.3(986)$ & $81.3(802)$ \\
\hline Current Use (Yes) & 9.3 (117) & $11.9(150)$ & $6.4(81)$ \\
\hline Intention to Use (Yes) & $13.5(170)$ & $15.9(200)$ & $5.0(63)$ \\
\hline Knowledge of Source (Yes) & $42.3(533)$ & $63.2(796)$ & $31.4(396)$ \\
\hline Discussed FP with Spouse (Yes) & $22.0(277)$ & $26.6(336)$ & $6.2(79)$ \\
\hline
\end{tabular}


Table 2

Percentage Distribution of Couples' Joint Characteristics and Their Fertility and Family Planning Attitudes

\begin{tabular}{|c|c|c|}
\hline Couple Characteristics & Percent & $(\mathrm{N})$ \\
\hline \multicolumn{3}{|l|}{ Residence } \\
\hline Urban & 29.6 & (373) \\
\hline Rural & 70.4 & (887) \\
\hline \multicolumn{3}{|l|}{ Current Parity } \\
\hline $0-3$ & 49.3 & $(621)$ \\
\hline $4-5$ & 26.3 & $(332)$ \\
\hline 6 and More & 24.4 & (307) \\
\hline (Mean) & (3.9) & (1260) \\
\hline \multicolumn{3}{|l|}{ Education } \\
\hline Both None & 49.0 & (617) \\
\hline Both Educated & 15.3 & (193) \\
\hline Wife None Husband Some & 33.6 & (423) \\
\hline Wife Some, Husband None & 2.1 & $(27)$ \\
\hline \multicolumn{3}{|l|}{ Fertility Desires } \\
\hline Both Want no More Children ${ }^{\mathrm{a}}$ & 25.6 & $(322)$ \\
\hline Both Want More Children & 49.8 & (629) \\
\hline Only Husbands Wants no More & 7.9 & (99) \\
\hline Only Wife Wants no More & 16.7 & (210) \\
\hline \multicolumn{3}{|l|}{ Family Planning Attitudes } \\
\hline Both Approve FP & 41.2 & (519) \\
\hline Both Disapprove & 20.2 & (254) \\
\hline Only Husband Approves & 25.2 & (318) \\
\hline Only Wife Approves & 13.4 & (169) \\
\hline \multicolumn{3}{|l|}{ Husband-wife Communication ${ }^{\text {b }}$} \\
\hline Both never Discussed & 39.4 & (297) \\
\hline Both Report Discussion & 23.6 & (496) \\
\hline Only Husband Approves & 17.8 & (224) \\
\hline Only Wife Reports Discussion & 19.2 & $(242)$ \\
\hline \multicolumn{3}{|l|}{ Current Use } \\
\hline Both not Using & 85.2 & (1074) \\
\hline Both Report Using & 6.4 & (81) \\
\hline Either Reports Using & 8.4 & $(105)$ \\
\hline Total & 100.0 & (1260) \\
\hline
\end{tabular}

a: Couples giving upto God/DK responses are included in the "want more" category under the assumption that they potentially are wanting more children.

b: This variable reports discussion between spouses on family planning and the number of children they want to have. 
Table 3

Percentage of Couples Practising Contraception, by Their Selected Characteristics and Fertility Attitudes

\begin{tabular}{lccrc}
\hline Couple Characteristics & Both Report Using & Either Reports Using & Total & $\mathrm{N}$ \\
\hline $\begin{array}{l}\text { Total } \\
\text { Residence }\end{array}$ & 8.4 & 6.4 & 14.8 & $(1260)$ \\
$\quad$ Urban & 16.0 & & & \\
$\quad$ Rural & 2.4 & 11.9 & 17.9 & $(373)$ \\
Educational Attainment & & 6.9 & 9.3 & $(887)$ \\
$\quad$ Both has no Education & 0.6 & & & \\
$\quad$ Only Husband some Education & 5.6 & 6.3 & 6.9 & $(617)$ \\
$\quad$ Only Wife some Education & 28.3 & 10.0 & 15.6 & $(423)$ \\
$\quad$ Both Educated & 23.7 & 7.5 & 35.8 & $(27)$ \\
Desired Fertility & & 11.5 & 35.2 & $(193)$ \\
$\quad$ Both Want no More Children & 14.8 & & & \\
$\quad$ Only Husband Wants no More & 5.0 & 12.8 & 27.6 & $(286)$ \\
$\quad$ Only Wife Wants no More & 8.0 & 20.4 & 25.4 & $(96)$ \\
$\quad$ Both Want More Children & 2.3 & 8.9 & 16.9 & $(229)$ \\
Family Planning Attitudes & & 4.4 & 6.7 & $(649)$ \\
$\quad$ Both Approve & 14.2 & & & \\
Only Husband Approves & 0.7 & 13.6 & 27.8 & $(519)$ \\
$\quad$ Only Wife Approves & 2.5 & 4.4 & 5.1 & $(318)$ \\
$\quad$ Both Disapprove & 0.0 & 9.7 & 12.2 & $(169)$ \\
Ideal Family Size & & 0.4 & 0.4 & $(254)$ \\
$\quad$ Wife: 0 - 3 Children & 19.6 & & & \\
$\quad 4$ and More & 11.2 & 11.2 & 30.8 & $(138)$ \\
Husband: 0 - 3 & 23.3 & 11.4 & 22.6 & $(356)$ \\
$\quad$ 4 and More & 10.4 & 15.7 & 39.0 & $(139)$ \\
& & 12.1 & 22.5 & $(302)$ \\
\hline
\end{tabular}

and 65 percent of husbands have given non-numeric or the 'upto God' response in this regard. This is unique in the case of Pakistan and raises the question whether couples stating a given ideal family size significantly differ in their reproductive control behaviour than those who are relatively more religious in their fertility attitudes. The ideal family size, on average, is slightly higher for husbands (4.6) than for wives (4.2).

Only those who wanted to have more children were asked the question regarding their preference for the gender of the next child. The figures indicate that both wives and husbands either want to have a boy as their next child or are indifferent about it. A very small proportion indicated a preference for a girl child. This clearly supports the evidence for son preference or for having a balanced family size among Pakistani couples. 
Although knowledge about family planning is widespread among both wives and husbands, a higher proportion of husbands have reported knowledge of the source of family planning service and the intention to use contraceptives. However, the level of reported discussion of family planning with the spouse is low. Only 22 percent wives and 26 percent husbands stated that they had discussed family planning or the desired number of children with their spouse in the past year.

To further look at the degree of concordance between wives' and husbands' responses to selected questions on reproductive goals and family planning attitudes, column 3 in Table 1 shows the simple percentage agreement for each category of variable. In general, about 60 percent of couples have given similar responses to questions on desired fertility, family size ideals, son preference, and family planning attitudes (agreeing either positively or negatively), while the remaining 40 percent have shown divergence in their responses.

\section{Couples’ Joint Characteristics and Fertility Attitudes}

Table 2 shows the distribution of some joint characteristics and fertility attitudes of matched couples. As expected, a majority of couples reside in rural areas (70.4 percent), and have five or fewer living children. The educational status of couples is quite low: 49 percent have no formal education at all; 15.3 percent have some education. In at least 33 percent of couples, husbands have some education, wives none. On the other hand, couples where only wives have some education and husbands none are very few in number (2.1 percent).

The table also shows that about 75 percent of couples have stated similar fertility desires. Of these, only 25.6 percent have expressed the desire for no more children as compared to about 50 percent who want more children. However, among 16.7 percent of couples, only wives want more children. Among 16.7 percent of couples, only wives want to stop childbearing even if husbands want more children, whereas the proportion of couples where only husbands want no more children is only 7.9 percent.

As for family planning attitudes, about 41 percent of couples have given favourable responses and only 20 percent disapprove of family planning. However, it appears that among those who differ in their attitudes, more husbands approve of family planning use despite their wives' disapproval (25.2 percent), whereas the proportion of couples with only wife's approval of family planning is 13.4 percent. How such differences in family planning attitudes influence the fertility control behaviour of couples would reveal something, if not much, about the dynamics of power relations between spouses in reproductive decision-making.

\section{Couples' Fertility Attitudes and Practice of Family Planning}

Table 3 shows how a couple's agreement on or differences in fertility and family planning attitudes are related with contraceptive use behaviour. As the table shows, 
about 27 percent of couples who want no additional child report using some form of contraception as compared to 6.7 percent who want to have more children. This implies that a very small proportion of couples use contraceptives for spacing purpose. In contrast, among couples who differ in their fertility desires, use of contraception is higher among those where only the husband wants no additional child (25.4 percent) than among those where only the wife wants to stop childbearing (16.9 percent). This clearly reflects that husbands' fertility desires are dominant in initiating contraceptive use behaviour among Pakistani couples. However, it is also interesting to note that about 72 percent of couples where both spouses want no additional children are reported as non-users, reflecting either lack of motivation among those couples to use contraceptives or the shortfall in family planning supply services. This situation is clearly reflective of a large unmet need or the existence of the KAP-gap in Pakistan, and merits attention of policy-makers and implementers of the family planning programme.

A couple's approval of family planning appears to be an important factor in the adoption of reproductive control behaviour, as 27.8 percent of couples where both spouses approve of family planning have reported using contraceptives compared to less than 1 percent of those who disapprove of it. In the case of a couple's differences in attitude, only wife approval results in higher use (12.2 percent) than where only the husband approves of family planning (5.1 percent); although a higher proportion of husbands than wives have reported favourable attitudes towards family planning (see Table 1).

The stated ideal family size of both wives and husbands shows large variation in use. Both the wives and the husbands who state their ideal family size as three or fewer children exhibit much higher use (30 percent and 39 percent, respectively) than those who want to have four or more children (22.6 percent and 22.5 percent). In addition to these attitudinal factors, the couple's education, in particular of the wife, and urban residence are related with higher use (see Table 3).

\section{A Multivariate Assessment of Couple Data in Contraceptive Use}

Since contraceptive use is influenced by a number of life-cycle and other factors, these results are re-examined in a multivariate analysis after controlling for woman's age, current parity, couple education, and residence to get a more precise explanation of a couple's reproductive attitudes on use. The results of logistic regressions used are shown in Table 4.

In Model 1, the effects of both wives' and husbands' fertility and family planning attitudes on contraceptive use are estimated. It appears that a couple's desire for no more children and approval of the use of family planning are significantly related with use. In particular, the log-odds of using contraceptives increase by 1.32 when both spouses want no more children as compared to those when both want more. 
Table 4

Logistic Regression Coefficients of Contraceptive Use, by Selected Couple Variables and Background Characteristics: Dhs, Pakistan, 1990

\begin{tabular}{|c|c|c|c|}
\hline Variable & Model 1 & Model 2 & Model 3 \\
\hline Constant & $-4.44(.21)^{* *}$ & $-5.62(.54) * * *$ & $-5.96(.56)^{* * *}$ \\
\hline \multicolumn{4}{|l|}{$\begin{array}{l}\text { Desire for Children } \\
\text { (Ref: Both Want More) }\end{array}$} \\
\hline Both Want no More & $1.32(.21)^{* *}$ & $1.09(.23)^{* * *}$ & $0.76(.27)^{* *}$ \\
\hline Husband Wants no More & $1.35(.29) * * *$ & $1.46(.32)^{* * *}$ & $1.23(.34)^{* * *}$ \\
\hline Wife Wants no More & $0.72(.25)^{* *}$ & $0.92(.27)^{* * *}$ & $0.74(.29)^{* *}$ \\
\hline \multicolumn{4}{|l|}{$\begin{array}{l}\text { Family Planning Attitudes } \\
\text { (Ref: Both Disapprove) }\end{array}$} \\
\hline Both Approve & $2.73(.47)^{* * *}$ & $1.63(.49)^{* * *}$ & $1.47(.50) * * *$ \\
\hline Husband Approves & $0.92(.53)^{*}$ & $0.57(.54)$ & $0.52(.55)$ \\
\hline Wife Approves & $1.80(.52)^{* * *}$ & $1.28(.54)^{* *}$ & $1.14(.55)^{* *}$ \\
\hline \multicolumn{4}{|l|}{$\begin{array}{l}\text { Ideal Family Size } \\
\text { (Ref: } 6+\text { upto God) }\end{array}$} \\
\hline Wife: 0 - 3 Children & & $0.33(.28)$ & 0.38(.31) \\
\hline 4 - 5 Children & & $0.51(.21)^{* *}$ & $0.44(.22)^{* *}$ \\
\hline Husband: 0 - 3 Children & & $1.02(.27)^{* * *}$ & $1.08(.28)^{* * *}$ \\
\hline 4 - 5 Children & & $0.73(.21)^{* * *}$ & $0.65(.22)^{* * *}$ \\
\hline \multicolumn{4}{|l|}{$\begin{array}{l}\text { Discussion of F.P. } \\
\text { (Ref: Both Never Discussed) }\end{array}$} \\
\hline Both Report Discussion & & $2.13(.35)^{* * *}$ & $1.95(.35)^{* * *}$ \\
\hline Either Reports Discussion & & $1.27(.34)^{* * *}$ & $1.14(-.34)^{* * *}$ \\
\hline \multicolumn{4}{|l|}{ Residence } \\
\hline Urban & & & $0.47(.21)^{* *}$ \\
\hline \multicolumn{4}{|l|}{$\begin{array}{l}\text { Couple Education } \\
\text { (Ref: Both no Education) }\end{array}$} \\
\hline Both are Educated & & & $0.41(.23)^{*}$ \\
\hline Either has some Education & & & $0.38(.38)$ \\
\hline \multicolumn{4}{|l|}{$\begin{array}{l}\text { Current Parity } \\
\text { (Ref: } 0 \text {-3 Children) }\end{array}$} \\
\hline 4 -5 Living Children & & & $0.77(.25)^{* * *}$ \\
\hline 6 or More Living Children & & & $0.42(.30)$ \\
\hline -2 Log Likelihood & 868.7 & 752.7 & 732.6 \\
\hline Model Chi-square & 185.6 (6 df) & $301.6(12 \mathrm{df})$ & $321.7(17 \mathrm{df})$ \\
\hline
\end{tabular}

$* \mathrm{P}<.10 ; * * \mathrm{P}<.01 ; * * * \mathrm{P}<.001$

Figures in the parenthesis are standard errors. 
Similarly, the log-odds of contraception increase by 2.73 when both spouses approve of family planning as compared to those who both disapprove. This means that couples who want no additional child are about 4 times more likely to be adopting fertility control than those who want more children, and couples who have favourable attitudes towards family planning are about 15 times more likely to use contraceptives than those who disapprove of it.

For couples who differ in their fertility attitudes, the effect of the husband's desire for no more children is much stronger as the log-odds of using contraceptives increase by 1.35 when only the husband wants no more children, compared to 0.72 when only the wife wants no additional child, indicating almost twice the difference in the log-odds of both the categories.

The reverse is true in the case of family planning approval where the log-odds of contraception increase by 1.80 when only the wife approves, compared to 0.92 when only the husband approves. The effect of the husband's approval is marginally significant which disappears after controlling for other fertility-related factors. These results, therefore, imply that although the husband's desired fertility is significant in the adoption of fertility control behaviour among couples, the wife's own approval of family planning is critical in increasing the likelihood of contraceptive use. These patterns remain the same after controlling for other variables in Models 2 and 3.

Considering Model 2 where the ideal family size of wives and husbands and couple discussion of family planning are included, it appears that couples giving numeric responses to the ideal family size question are more likely to use contraceptives than those who have given the "upto God" or non-numeric responses. In particular, the husband's stated ideal number $0-3$ children has the strongest effect on use. For the wives, the coefficient of the ideal family size is significant for only 4-5 children as compared to those who have given the "upto God" responses on fertility.

Couple discussion about family planning is highly significant in predicting use. The effect is the strongest for 'both spouses reporting discussion' than for the 'either category' in comparison to those who have never discussed family planning together. The coefficients remain highly significant even when all other variables are controlled.

Among the background factors included in Model 3, the urban as compared to the rural residents and couples with 4-5 living children as compared to those with current parity 0-3 are significant in predicting use. As expected, educated couples are more likely to use contraception as compared to uneducated ones. However, the coefficient for both spouses educated has emerged as marginally significant in predicting use, whereas the coefficient for those where either spouse is educated is not significant. This category comprises couples where a large majority of husbands are educated while wives are not, implying that husband's education is not important in affecting the couple's adoption of fertility control. Woman's age has not emerged as a significant factor in predicting use and, therefore, is not reported in the Model. 
Overall, these results tend to suggest that a couple's fertility and family planning attitudes are important in influencing reproductive control behaviour in Pakistan. This has been largely explained by the dynamics of gender relations with respect to fertilityrelated attitudinal variables rather than their age or achieved parity. These results also suggest that both partners play a role in the adoption of contraception, considering the significance of couple discussion in increasing the likelihood of use.

\section{CONCLUSIONS}

The findings of this analysis show that about 60 percent of couples in general have given similar responses (agreeing either positively or negatively) to several fertility-related questions, whereas the remaining 40 percent differ in their attitudes. Although this divergence may partly be a product of the interviewing or data collecting procedures, it is likely that the majority of spouses with a rural background, lack of education, and low communication may not know their partner's attitudes. This lack of knowledge and incompatibility between spouses may be the hindering factors in fertility decision-making, and have important implications for the adoption of contraceptive use. The precise reasons for discrepancies between the responses of wives and husbands are difficult to elucidate from these types of data. Our findings, however, imply that information on fertility-related questions by gender is helpful in improving our understanding of family planning decision-making among Pakistani couples.

The results suggest that a couple's joint approval and discussion of family planning have the strongest effect on promoting contraceptive use. However, wife's approval of family planning is highly significant in determining use whether or not the husband approves. This has important implications in terms of enhancing the use of family planning if the services are made accessible to those women.

The major finding is that it is mostly women, not men, who want fewer children, but they are also more likely to disapprove of family planning. This result finds partial support from previous research, which concluded that lack of demand for contraception in Pakistan was the dynamic of a male-dominated society in which women who bear the children may desire to have fewer children but men who reap the benefits want more [Robinson, Shah and Shah (1981)]. However, women's greater likelihood of disapproving of family planning than men could be due to high levels of illiteracy and adherence to traditional attitudes and behaviour.

Although a greater proportion of men than women want more children, approve of family planning, and have the knowledge of a source of supply, a very small proportion (11.9 percent) have reported actual use of contraception. The favourable attitude knowledge, however, indicates an opportunity to reach men with family planning and reproductive health messages.

Another important finding emanating from the results in Table 4 is that the husband's desire for no additional children has a greater effect on increasing the 
likelihood of use than has his wife's. This implies a strong role for the husband's fertility attitude to family planning. In a strong patriarchal society like that of Pakistan, where a small proportion of women are literate, ignoring the influence of husbands in family decision-making and focusing on women alone in promoting contraceptive prevalence may seriously limit the success of the programme. This finding is supported by the results of research done earlier in Pakistan [Mahmood and Ringheim (1993)], and suggests that husbands should be made equal targets of such programmes to assist couples in meeting their reproductive goals and making the family planning programme more successful.

It is also found that discussion between spouses about family planning contributes significantly to increasing contraceptive use. In Pakistan's socio-cultural context, where most couples do not jointly make decisions or openly discuss or share information on family planning, it appears that educational campaigns encouraging husband-wife communication may improve the chances of effective family planning.

The results in Table 4 have clearly indicated the role of couple agreement in increasing the use of family planning. The analysis done, however, has raised the important policy question as to why those couples who want no more children or approve of family planning are not adopting fertility control behaviour. As the figures indicate, only about 27 percent of couples who both want no more children or both approve of family planning have reported using contraceptives, leaving the majority in the non-user category. In finding answers to this type of questions and issues, we may suggest that while education of women and the expansion and improvement of programme services are clearly necessary, increasing the awareness of husbands about the advantages of child-spacing and having small families should be emphasised. Considering the recent demographic changes in Pakistan in terms of a rising trend in contraceptive use and gradually declining fertility, it is important that efforts should be maximised for making the services accessible to eligible couples, for raising their awareness about reproductive health, and for promoting male involvement in family planning programmes.

The evidence of a latent demand for fertility control within the same household and the disagreement on fertility control behaviour among couples indicates that the family planning programme could be more successful if a consensus and approval on fertility desires among couples could be reached. In this regard, more information and research are needed to find out the best approaches to reach out to women and men in traditional settings, and to resolve differences in their fertility and family planning attitudes. Obtaining qualitative information and undertaking in-depth interviewing about family planning are important so as to know who takes the initiative to control fertility, who acquires and chooses the method, who decides about the family size, what circumstances inhibit women to adopt contraception, etc. This may be useful towards a more precise explanation of the gender-related issues and couple attitudes towards family planning adoption in Pakistan. 


\section{REFERENCES}

Arnold, Fred (1992) Sex Preference and Its Demographic and Health Implications. International Family Planning Perspectives (183): 93-101.

Beckman, Linda J. (1983) Communication, Power, and the Influence of Social Network in Couple Decisions on Fertility. In R. A. Bulatao and R. O. Lee (eds) Determinants of Fertility in Developing Countries: A Summary of Knowledge Vol. 2. New York: Academic Press.

Coombs L. C., and D. Fermandez (1978) Husband-Wife Agreement About Reproductive Goals. Demography 15 February: 57-74.

Coombs, L. C., and M. C. Chang (1981) Do Husbands and Wives Agree? Fertility Attitudes and Later Behaviour. Population and Environment 4: 109-127.

Ezech, Alex Chica (1993) The Influence of Spouses over Each Other's Contraceptive Attitudes in Ghana. Studies in Family Planning 24:3 163-174.

Govendasamy, Pav, and Anju Malhotra (1994) Aspects of Female Autonomy in Egypt: What Can We Learn from DHS Data? Paper presented at the Annual Meeting of Population Association of America (PAA). May 5-7, Florida, Miami.

Koenig, M. A., G. B. Simmons, and B. D. Misra (1984) Husband and Wife Inconsistencies in Contraceptive Responses. Population Studies 38: 281-298.

Lloyd, Cynthia (1993) Family and Gender Issues for Population Policy. The Population Council, New York. (Working Paper No. 48.)

Mahmood, Naushin, and Karin Ringheim (1993) Desired Fertility in Pakistan: What is the Influence of Husbands? Paper presented at the Annual Meeting of Population Association of America (PAA) in Cincinnati, Ohio. April 1993.

Mason, K., and A. Taj (1987) Differences between Women's and Men's Reproductive Goals in Developing Countries. Population and Development Review 134: 611638.

Mott, F. L., and S. H. Mott (1985) Household Fertility Decisions in West Africa. Studies in Family Planning 16:2 88-89.

Nag, Moni (1991) Sex Preference in Bangladesh, India and Pakistan and Effects on Fertility. Population Council Research Division, New York. (Working Paper No. 27.)

Robinson, Warren, M. A. Shah, and N. M. Shah (1981) The Family Planning Programme in Pakistan: What Went? International Family Planning Perspectives 7: 85-92.

Salway, Sarah (1994) How Attitudes Toward Family Planning and Discussion Between Wives and Husbands Affect Contraceptive Use in Ghana. International Family Planning Perspective 20:2 44-47.

Sathar, Z., N. Crook, Christine Collum, and S. Kazi (1988) Women Status and Fertility in Pakistan. Population and Development Review 14:3 415-432. 
Shah, N. M. (1974) The Role of Inter-Spousal Communication in Adoption of Family Planning: A Couple Approach. The Pakistan Development Review 13:4 452-469.

Thomson, E., E. McDonald, and L. Bumpass (1990) Fertility Desires and Fertility: Hers, His and Theirs. Demography 27:4 574-584. 